\title{
Polarization and Effects on Hidden Node/Shadowing Margin for TVWS
}

\author{
A. Aragón-Zavala, T.W.C. Brown, Member, IEEE and Gerardo Castañón, Member, IEEE
}

\begin{abstract}
Dual polarized measurements comparing the received power of a line of sight broadcast signal in the ultra-high frequency (UHF) band with received power in suburban streets and indoors including high rise buildings are presented in this paper. Both the co-polarized and cross-polarized fades are therefore measured in the different locations. Their purpose is twofold: a) to identify the importance of using polarization when considering hidden node margins in spectrum sensing of television white spaces and b) to indicate how polarization can be beneficial in improving the shadowing margin to increase the path loss from the secondary to primary user and thus further protect digital terrestrial television receivers from harmful interference. The impact of polarization in open environments with low clutter or near windows inside high rise buildings is more significant than in densely cluttered spaces experiencing strong multipath.
\end{abstract}

Index Terms - TVWS, indoor propagation, measurement, hidden node margin.

\section{INTRODUCTION}

TELEVISION broadcasting has evolved from the early days of analogue transmissions to digital terrestrial broadcasting, where hundreds of simultaneous channels can be transmitted with improved signal quality. In many countries this has caused analogue transmissions to be switched off and hence this part of the spectrum has been released for other services. In this context, the term "white space spectrum" refers to frequencies that are not being used by existing licensees at all times or at all locations. A white space device (secondary user) can make use of these frequencies provided that the risk of harmful interference to the licensed (primary) users of the spectrum can be appropriately managed.

In order to identify channel occupancy accurately, several methods have been proposed. In geo-location databases [1]-[4], location-aware wireless devices are assisted by such databases and information on white space availability is provided, taking into account existing licensed use. Thus, geo-location databases track which channels are available in each geographic region. On the other hand, spectrum sensing [5]-[8] has been 
designed to reliably sense the target signals (i.e. at the desired frequencies) sometimes under challenging scenarios including low Signal-to-Noise Ratio (SNR) and strong adjacent channel interference (ACI). Spectrum sensing to detect the presence of primary signals is one of the most important functionalities of cognitive radios. Unlike the geo-location requirements, the spectrum sensing requirements are in terms of the received power of the signal, not the field strength [9]. Therefore, spectrum sensing will be required to support geo-location databases since cognitive radios will need to detect the presence of primary signals to avoid interference to incumbent users at the same time as updating existing geo-location database information.

Radio propagation has an important effect on how these signals could be detected for various types of scenarios. Perhaps the most critical scenario is when the signals have to propagate through walls, along roads and inside buildings. Thus special attention should be given to penetration losses at television white space (TVWS) bands in two possible ways:

1. For the so called Hidden Node Margin (HNM), which will mean that if the penetration loss is too great it may prevent the white space device from sensing spectrum that is in use and potentially cause interference as a consequence of transmitting at the non-sensed frequency.

2. To give suitable indication as to the additional path loss or reduced coupling to primary users, which will be assisted by placing white space devices into cluttered local areas where they are "isolated" such as within a street or building, thus significantly reducing risk of interference to the primary user (or victim device). This can be considered as a shadowing margin.

Note however that in some instances in this paper, the term path loss margin (PL margin) is used. This is to mean that the PL margin measurements taken can be interpreted in terms of either HNM or shadowing margin. This paper describes a series of radio measurements undertaken to show the importance of using the correct polarization in the case of 1 , while in the case of 2, cross-polarization can have benefit. Two measurement campaigns were performed. The first one in Guildford, UK was designed to complement results obtained in [10], which previously identified the benefit of using polarization for spectrum sensing outdoors, but did not specifically measure the hidden node margin effect, which was possible to analyze in some of the same outdoor locations. The second measurement campaign at Queretaro, Mexico, consisted of a dozen buildings, which were tested having distinct case scenarios to assess the effects of propagation losses and polarization on the hidden node / shadowing margins both inside the buildings and at different floor levels. 
Both sets of results therefore aim to evaluate the polarization effect both at street level and in indoor scenarios from which minimal changes in margin can be deduced.

The paper is organized as follows: section II presents the specific details of both measurement campaigns that were conducted in the UK and Mexico; section III shows the results from these measurements in terms of statistical distributions of the margins measured including the effects of polarization and building height; section IV analyses the results in terms of mean value ratios and discusses scenarios where polarization is of benefit or important to use. Finally section V presents conclusions followed by an Appendix of useful raw data in section VI.

\section{Measurement Campaigns}

\section{A. Guildford, Surrey, UK}

The selected area for the HNM measurements was around Stoke Park, in Guildford, UK (Fig. 1). In each case, reference measurements were conducted having a line of sight with the local transmitter 3km away and further dual polarized measurements were captured at street level or indoors depending on the location in order to measure the PL margin. A further benefit of the measured locations was their variability in altitude, which changed the angle of elevation from as low as $3.5^{\circ}$ to $10^{\circ}$. For such elevation angles, when considering these measurements in terms of shadowing margin, it assumes reciprocity such that the mean PL margin is comparable when a white space device (WSD) at the same location is propagating interference to a victim device at the same elevation some distance away. One important difference between the test case and a real case would be that the victim device will not have the same antenna pattern as the television transmitter used, though an Uda-Yagi antenna would have an expected azimuth beamwidth of $30^{\circ}$, which for large distances greater than $2 \mathrm{~km}$ (the same as the measurements), the antenna beam would cover a scattering area beyond $500 \mathrm{~m}$ diameter, which is well beyond the distance of the local shadowing objects. Therefore, based on the principle of reciprocity, the test case suitably matches the PL margin that would be measured as an uplink from a WSD to a victim device thus giving an indicative shadowing margin result.

Measurements were taken in eight different areas, in which reference measurements were taken in a line of sight from the transmitter so that the HNM or shadowing margin could be suitably calculated for the measurement locations in each area. It was also ensured that the reference measurement was taken within $150 \mathrm{~m}$ of each measurement location so that there would be negligible difference in free space path loss when calculating the path loss margin in the shadow. The eight locations are illustrated in Fig. 1 accompanied by a 
larger map indicating the position of Stoke Park relative to the transmitter site.

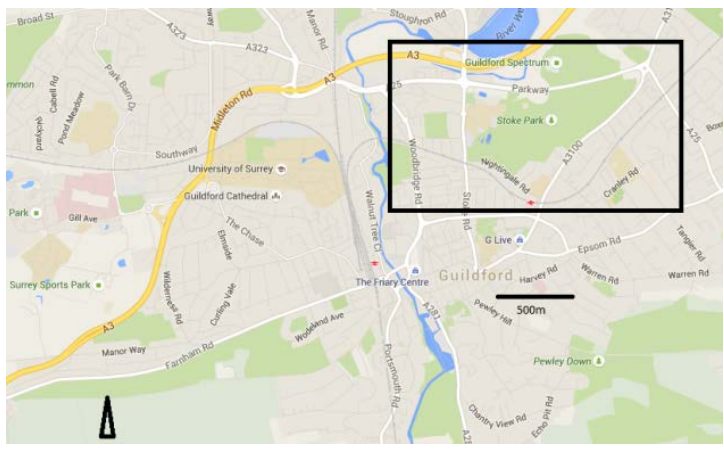

(a)

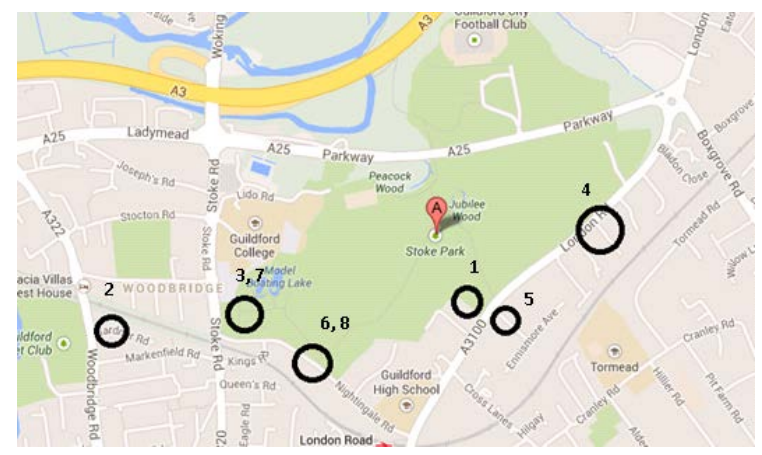

(b)

Fig. 1. Maps showing (a) the position of the transmitter to the measurement area and b) the measurement area in Stoke Park, Guildford

Three areas numbered in Fig. 1 (b) were measured outdoors with relatively low clutter, named in Table A1 (b) in the appendix as School (Area 1), Gardner Road (Area 2) and Wall (Area 3). Three other areas were outdoors at street level with significant clutter named as St. Margarets (Area 4), Eisenmore (Area 5) and Lower Street (Area 6). Finally two indoor locations were chosen as public toilets, named as Gents Toilets and Gents Toilets 2 (Areas 7 and 8).
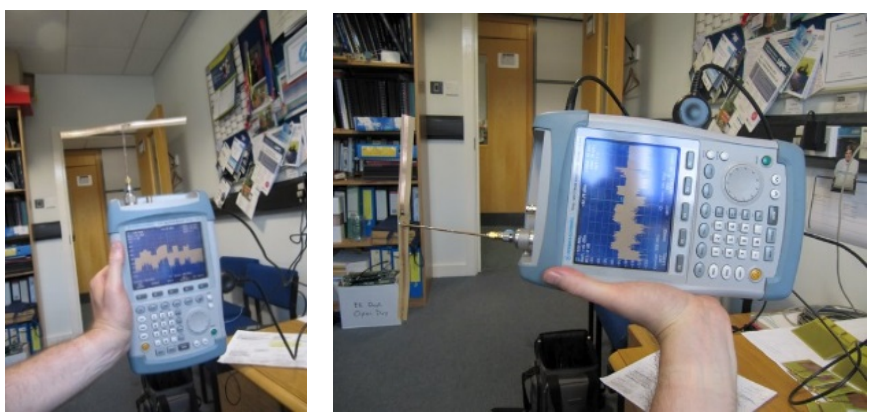

Fig. 2. V and H polarization handheld positions

A Rhode \& Schwarz FSH3 portable handheld spectrum analyzer was employed for the measurements, connected to a laptop computer to capture data. Since polarization effects were of interest, the portable spectrum analyzer was held at head level at two different positions, as depicted in Fig.2, to compare vertical and horizontal polarized effects. A dipole antenna was fabricated for the frequency range of interest (600$720 \mathrm{MHz}$ including channels 40-51), while the captured data was kept on a laptop for post-processing. The resolution and video bandwidths were set to $10 \mathrm{kHz}$, which is below the expected sensing bandwidth of a WSD [11], though the measurement noise floor is minimized this way. This will allow the measurements to identify cases where a WSD may not detect spectrum within its own higher noise floor due to mismatched polarization. The azimuth pattern of the dipole used was measured both in free space and also in the presence 
of a human body at arm's length as it would be when measuring in order to determine the impact of the body on the antenna’s omni directionality. It was found that for $\pm 50^{\circ}$ directly behind the body, the antenna gain was up to $10 \mathrm{~dB}$ less than without the body present, while at all other angles, the gain was comparable. To avoid inaccuracy in both reference measurements and path loss margin, measurements were taken with the antenna always facing the transmitter source, where in this range there was an antenna co- to cross-polar ratio in excess of 10dB thus suitable for distinguishing polarizations in the measurement environment.

\section{B. Querétaro, Mexico}

The second set of measurements were conducted in two main locations; the first one was buildings in Tecnológico de Monterrey, Campus Querétaro, Mexico (ITESM-CQ); and the second one consisted of various street locations at different elevation angles from the television (TV) transmitter site. The distance from the transmitter at these two locations was $9 \mathrm{~km}$ and $5 \mathrm{~km}$ respectively and the incidence angles were within a range from $2.7^{\circ}$ to $12.7^{\circ}$. Reference measurements were taken at rooftop level using vertical polarization whereas dual polarized measurements were subsequently collected indoors and outdoors, and at different height levels in large buildings. Corridors as well as densely cluttered spaces were tested, taking also in-building depth into consideration. Channel $36(602-608 \mathrm{MHz})$ was selected since it has the strongest transmissions thus maximizing measured signal to noise ratio for in-depth building measurements.

Measurements taken in both main locations, for purposes of analyzing results, were divided into four main scenarios (where also in the results the Guildford measurements were suitably merged) as follows:

- Deep Indoor - Densely cluttered deep indoor spaces, such as classrooms, library bookshelves, toilets.

- Window - Indoor spaces but close to windows or on a balcony.

- $\quad$ Outdoor - Open spaces outdoors at street level surrounded by buildings.

- House - Rooms inside a residential house both upstairs and downstairs. 


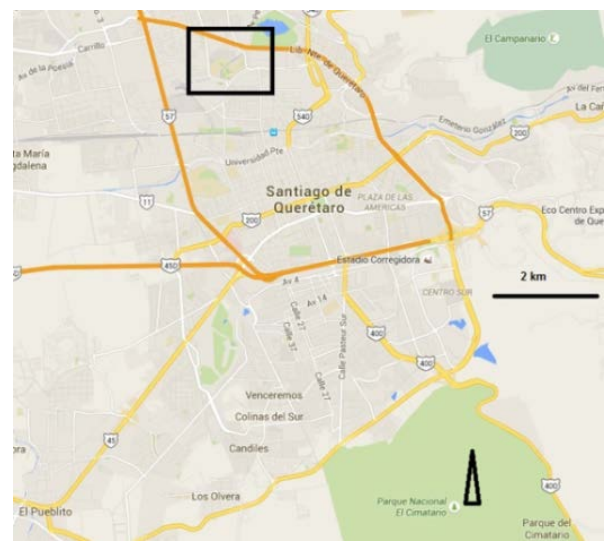

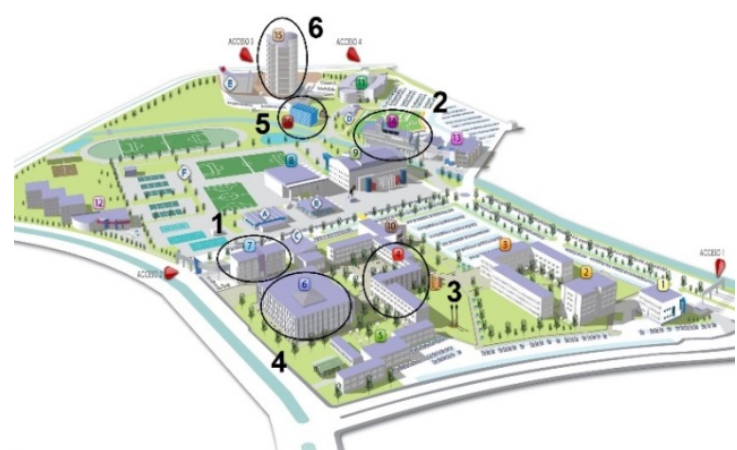

(b)

Fig. 3. (a) Map indicating the site of ITESM-CQ relative to the television transmitter and (b) measurement locations on site

For ITESM-CQ, signal strength measurements were collected in six different campus buildings (Fig. 3). The choice of buildings was mainly due to their architecture, availability for testing various spaces, accessibility to rooftop to conduct reference measurements there and their suitability to establish different case scenarios. Tested campus buildings had one or more case scenarios and invariably all had reference rooftop measurements, with a direct line-of-sight to the TV transmitter. The nature of the buildings, with specialized architecture, labelled in Fig. 3 are described as follows:

Administrativo (Building 1). A multi-storey building of offices and reception halls at ground floor level. High penetration losses were detected here where the deep indoor scenario was the predominant, while other measurements were taken near the window.

Arquitectura (Building 2). This building has line-of-sight with the TV transmitter in all floors, with balconies, classrooms and toilets so that deep indoor, window and outdoor scenarios could be measured.

Aulas 4 (Building 3). This is a large classroom building where due to its size and orientation, measurements were conducted in the closest edge of the building facing towards the TV transmitter site enabling deep indoor and window scenarios to be compared.

Biblioteca (Building 4). A library with three stories hosting computing classrooms, labs, and an exposition hall, open areas and study rooms accommodating deep indoor and window scenarios.

CIMA (Building 5). The building hosts research and development labs and specialized machinery (Fig. 4), which although an open area inside, it is a largely deep indoor scenario. 


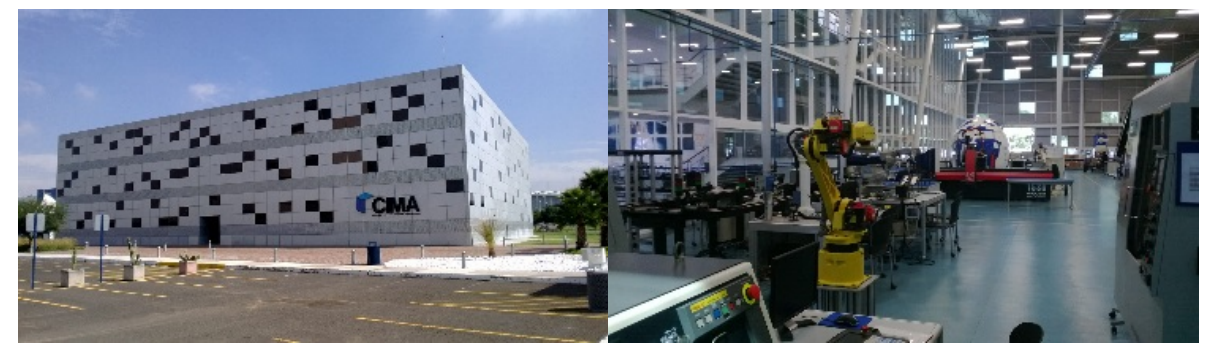

(a)

(b)

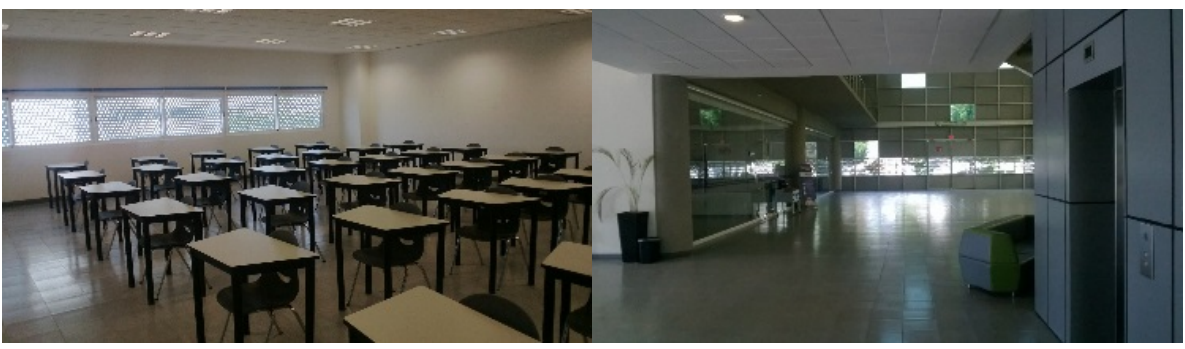

(c)

(d)

Fig. 4. CIMA building; (a) external view; (b) machinery area; (c) classroom; (d) hall in ground floor

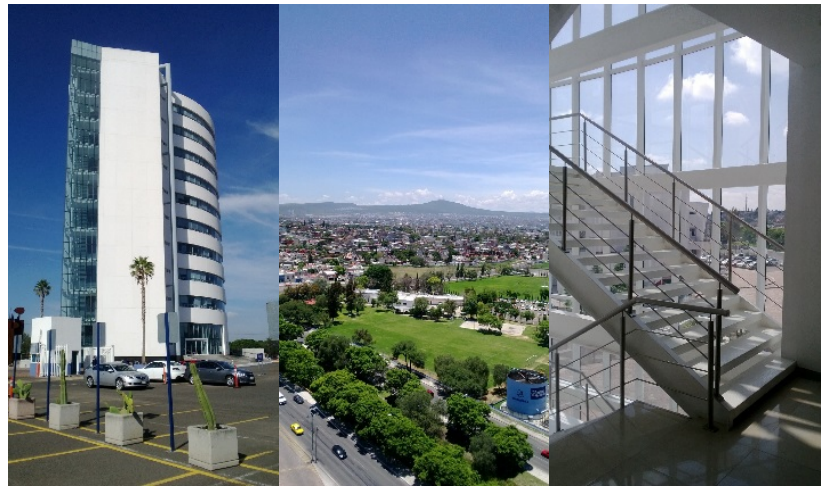

(a)

(b)

(c)

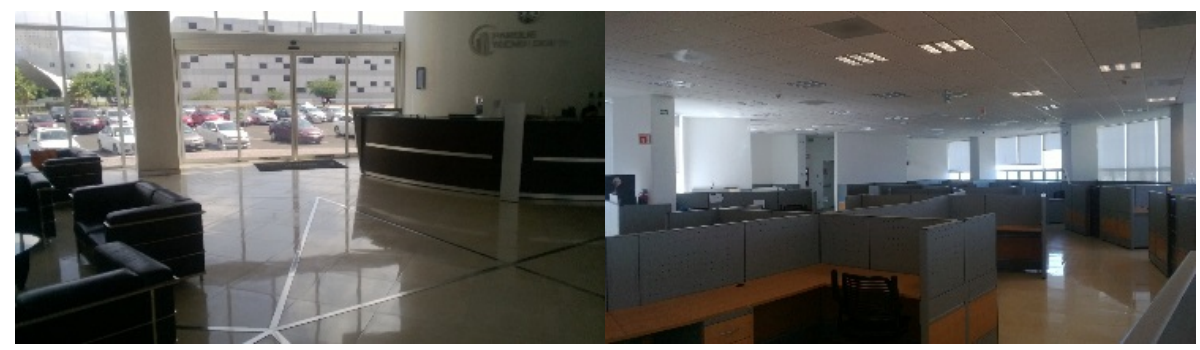

(d)

(e)

Fig. 5. Technology Park; (a) external view; (b) rooftop measurement; (c) area near window at upper level; (d) reception area; (e) offices in $7^{\text {th }}$ floor

Technology Park (Building 6). This is a multi-storey building with eleven floors, mainly offices and meeting 
rooms (Fig. 5). There is a line-of-sight view with TV transmitter on all floors, having large glass windows that allow sufficient signal penetration. The layout of each floor is very similar, thus making the comparison of HNM effects due to height and in-building depth ideal where both deep indoor and window scenarios can be compared.

To cover both outdoor and house scenarios, measurements were conducted at street level and in houses where the distance to the transmitter and the elevation angle for each measurement point is shown in Table 1. The transmitter site was located on a mountain, Cimatario, at a height of $2350 \mathrm{~m}$ and from these altitudes the distances to the site were considered to compute the elevation angles between $2.7^{\circ}$ and $12.7^{\circ}$ at test sites.

An Agilent FieldFox handheld spectrum analyzer N9913A was used for the measurements, including a fabricated dipole antenna resonating at a frequency of $603 \mathrm{MHz}$ and used in the same way as the spectrum analyzer in the Guildford measurements to compare polarizations. Additionally the resolution and video bandwidth was also set to $10 \mathrm{kHz}$ and data was captured onto file for analysis. It should also be noted that additionally measurements were taken on the rooftop at the Technology Park and Administrativo locations behind a wall thus accommodating some further outdoor scenario measurements. All the spaces in all the two main locations, with their corresponding average margins measured are listed in Table A1 (a) in the appendix for reference.

\begin{tabular}{|l|l|l|l|l|}
\hline Location & Description & Altitude & $\begin{array}{l}\text { Distance } \\
\text { to site }\end{array}$ & $\begin{array}{l}\text { Elevation } \\
\text { angle }\end{array}$ \\
\hline Cimatario & $\begin{array}{l}\text { TX site for } \\
\text { broadcasting }\end{array}$ & $2350 \mathrm{~m}$ & $0 \mathrm{~km}$ & $0^{\circ}$ \\
\hline $\begin{array}{l}\text { Puerta } \\
\text { Real }\end{array}$ & $\begin{array}{l}\text { Household } \\
\text { indoor/outdoor }\end{array}$ & $1800 \mathrm{~m}$ & $6 \mathrm{~km}$ & $5.2^{\circ}$ \\
\hline ITESM & University & $1930 \mathrm{~m}$ & $9 \mathrm{~km}$ & $2.7^{\circ}$ \\
\hline $\begin{array}{l}\text { Vista } \\
\text { Real }\end{array}$ & $\begin{array}{l}\text { Street level } \\
\text { outdoor }\end{array}$ & $2100 \mathrm{~m}$ & $4.3 \mathrm{~km}$ & $3.3^{\circ}$ \\
\hline $\begin{array}{l}\text { Camp. } \\
\text { Italiana }\end{array}$ & $\begin{array}{l}\text { Steet level } \\
\text { outdoor }\end{array}$ & $1900 \mathrm{~m}$ & $2 \mathrm{~km}$ & $12.7^{\circ}$ \\
\hline Tejeda & $\begin{array}{l}\text { Street level } \\
\text { outdoor }\end{array}$ & $1885 \mathrm{~m}$ & $5 \mathrm{~km}$ & $5.3^{\circ}$ \\
\hline Marcelina & $\begin{array}{l}\text { Street level } \\
\text { outdoor }\end{array}$ & $1830 \mathrm{~m}$ & $9.2 \mathrm{~km}$ & $3.2^{\circ}$ \\
\hline
\end{tabular}

Table 1. Site characteristics for ITESM-CQ and outdoor venues considered for street level measurements

\section{Results - STATISTICAL DistRIBUtions OF HNMS}

Since a resolution bandwidth of $10 \mathrm{kHz}$ was used for all measurements taken, a set of comparable cumulative distribution (CDF) statistics could be obtained via post processing from the frequency selective channel. To calculate the HNM, an 8MHz broadcast channel was chosen with the highest signal to noise ratio 
which sufficiently penetrated into the measured environment. When processing the reference measurement of this channel, an average was taken, as shown from the measurements with solid lines in Fig. 6, using five measurement iterations. These iterations were taken at five different points approximately $1-2 \mathrm{~m}$ from each other to accommodate spatial effects and it can be found transmission was measured over a $6 \mathrm{MHz}$ frequency band. This derived a suitable reference level where the received power in a given location could be calibrated relative to this average giving a PL margin measurement. The dotted lines in Fig. 6 show an example of four measurement iterations taken in a shadowed location with vertical polarization, which are clearly lower than the reference case.

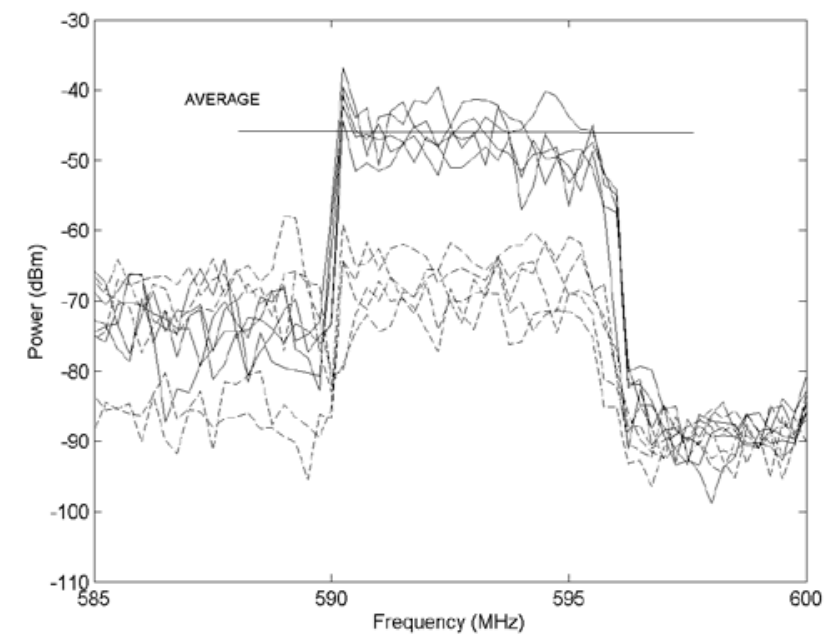

Fig. 6. Example comparison of five measured reference iterations (solid lines) and four measured iterations in a shadowed location (dotted lines)

By measuring a power level at a fixed $10 \mathrm{kHz}$ frequency bin, at a fixed time instant and in a fixed point in space and calculating the ratio of this power relative to the mean power of the reference measurement, this is defined as an instantaneous HNM. By calculating all possible measured values of instantaneous HNM, a distribution can be formed as a CDF plot. It must be noted that this distribution is formed not only by the frequency selective channel, but also due to the instantaneous power level transmission from the broadcast transmitter, which is not constant over time. Therefore the distribution is not an accurate measurement of what could be termed instantaneous shadowing margin for the $10 \mathrm{kHz}$ sample but rather concerned with the impact of the environment when detecting spectrum usage. Note that only measurements taken in Querétaro, Mexico were used in this section as the Guildford, UK measurements did not have sufficient data for such analysis. An aggregate CDF plot showing for the four measurement scenarios (i.e. outdoor, deep Indoor, window and house) can be compared and are plotted in Fig. 7. Deep indoor does not benefit from polarization 
as much as window and house cases. This is expected since deep indoor environments are more cluttered and subject to more reflections and multipath, which causes de-polarization effects. The impact of polarization for window and house cases on the other hand is as high as $10 \mathrm{~dB}$.

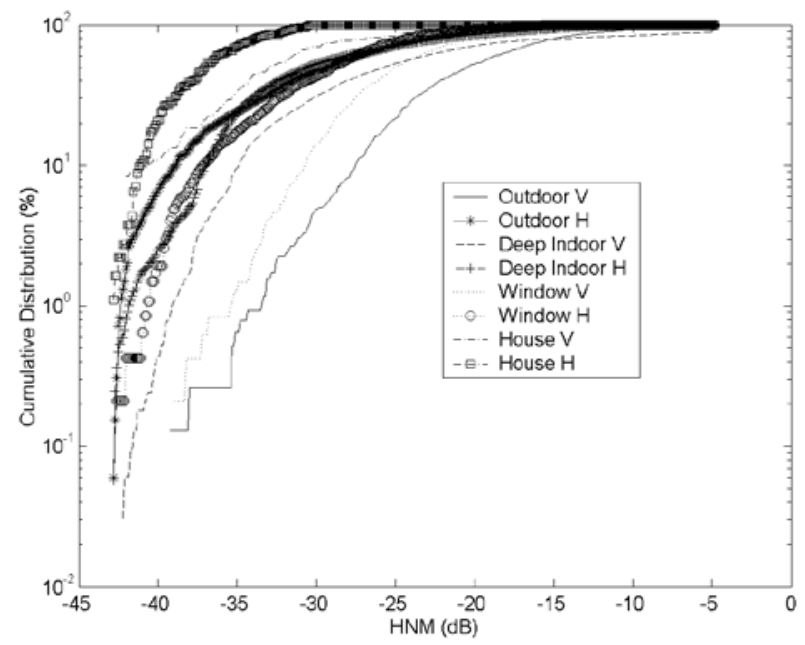

Fig. 7. Aggregate CDF of distinct scenarios to assess impact of polarization on instantaneous HNM

To assess the impact of building floor level on instantaneous HNM and polarization, Figs. 8 and 9 make a comparison in two different propagation scenarios. In Fig. 8 deep indoor instantaneous HNM aggregate CDF plots have been produced to compare the effect of different floor levels. Here polarization does not make any distinguishable difference regardless of floor level, but specific clutter has more impact on the propagation effects and the instantaneous HNM regardless of polarization. On the other hand, Fig. 9 compares aggregate CDF plots for instantaneous HNMs obtained from measurements taken near windows, for which polarization definitely has an impact. There is a high polarization margin at all levels except level 1 . All levels have a low obstructed LOS with transmitter site, though level 1 is a mezzanine area with different layout from the rest of the Technology Park building levels and therefore there is a higher obstructed LOS than the rest of the floors. In fact, level 1 has very few windows and some offices that increases the amount of clutter there. 


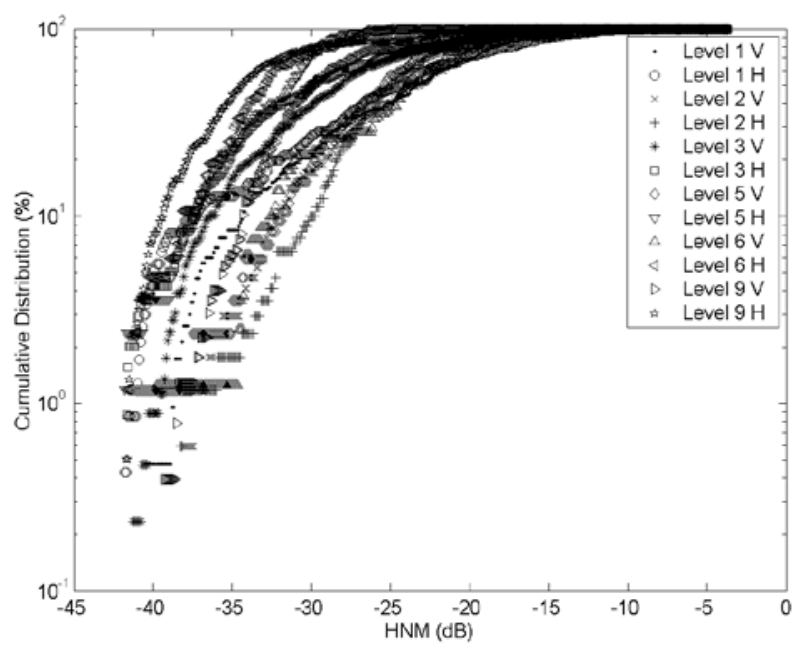

Fig. 8. Effect of building floor level on instantaneous HNM - deep indoor where polarizations have no clear difference

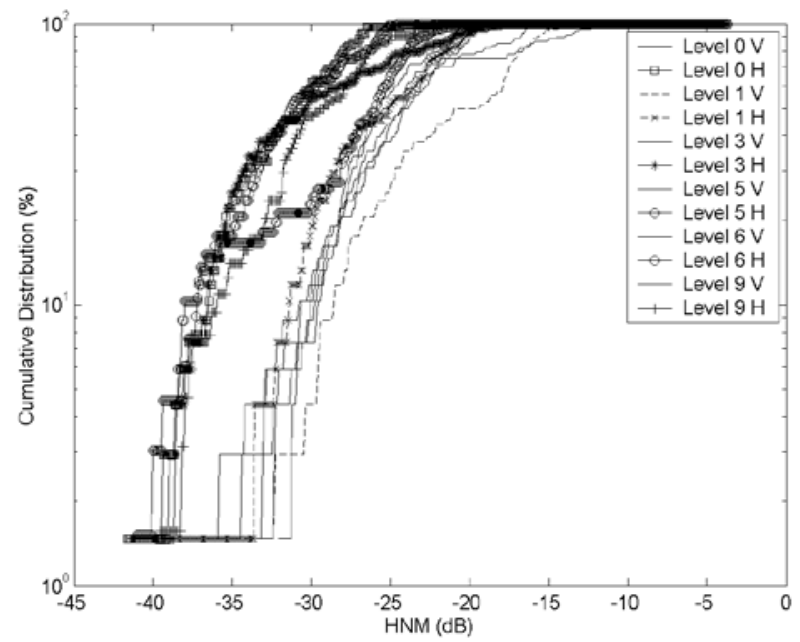

Fig. 9. Effect of building floor level on instantaneous HNM - near windows showing change in HNM with horizontal polarization

\section{Results - MeAn VAlue RAtio ANALysis}

As shown in Table A1 in the appendix in section VI, the vertical PL margin is computed by first taking the mean reference level as described in section III, secondly by taking the mean of five iterations of a vertical measurement in the same way and resolving the ratio between the two. This can be similarly computed for a horizontal measurement and hence a vertical to horizontal ( $\mathrm{V}$ to $\mathrm{H})$ margin can be found as the ratio between the mean vertical and horizontal. The PL margin as a ratio between two mean powers can be interpreted either as a HNM or as an indicative shadowing margin based on the assumptions described in section I.

A better way to visualize the impact of polarization in PL margins is by looking at the plots in Figs. 10 and 11, which show V to $\mathrm{H}$ ratios and PL margins for various sample numbers. A "sample" is taken from a 
physical space that has been measured and for which the PL margin has been calculated. As this data is now merging both Guildford and Querétaro results together, the scenarios have been slightly redefined from section III as follows:

- Deep indoor and house - merging these two previous scenarios together

- Window - the same scenario as before

- $\quad$ Outdoor at street level - taking the outdoor scenarios in a street.

- Outdoor with low clutter - where for example a wall is the only obstruction to the line of sight and therefore it is low clutter.

In Fig. 10 the $\mathrm{V}$ to $\mathrm{H}$ ratio for these four scenarios is plotted and sorted in ascending order. Corresponding to this, Fig. 11 shows the vertical PL margins with solid curves and horizontal PL margins and dotted curves with the samples in the same order as Fig. 10. It is worthy of noting that these plots should be shown as discrete marker points, but the comparisons between solid and dotted curves in Fig. 11 would lack clarity and thus curves have been applied to better illustrate the results. Furthermore the curves for the four different scenarios have been offset on the x-axis for purposes of comparison. Different colors have been applied to the four different scenarios as shown in the legend. To see the linkage between the two graphs, the difference between the PL margins in decibels for a single sample corresponds to the $\mathrm{V}$ to $\mathrm{H}$ ratio for the same sample in Fig. 10. This therefore helps to identify that the majority of cases with a low $\mathrm{V}$ to $\mathrm{H}$ ratio have a high vertical (and likewise horizontal) PL margin. This is also the case in vice versa. For reported PL margins generally less than $30 \mathrm{~dB}$ for all spaces, polarization can be used to better protect the victim devices or rather polarization is essential to use in spectrum sensing, with $\mathrm{V}$ to $\mathrm{H}$ ratios of 3-20dB, which strongly depends on the environment. This is less profound for indoor scenarios particularly with higher margins than $30 \mathrm{~dB}$, since multipath associated with clutter and other propagation mechanisms strongly de-polarizes the transmitted signal.

It is worthy of noting for the deep indoor scenarios that there are three spaces where the $\mathrm{V}$ to $\mathrm{H}$ ratio is below 0dB, thus the co-polarization gives a higher PL margin than the cross polarization. The instances where this happened were in the CIMA building, which is a shielded type of structure with a large opening at the entrance and relatively small windows at the highest levels as shown in Fig. 4. Some surrounding clutter in the vicinity of the toilets and corridor were where this effect occurred. The degree of depolarization was so high that the signal was strongly affected by multipath that the horizontal component was on average received 
at a higher level than the vertical component. The PL margin is nonetheless already high (above 10dB) in these scenarios that the polarization adds little further loss. It is also worthy of noting spaces 52-56 where the PL margin is below 0dB for four of those samples. Therefore the measured space has a lower path loss than the reference case. These scenarios occur in Arquitectura on the corridor at different levels where another neighboring building is creating constructively interfering reflections at the vicinity of the lower levels thus causing the average vertical PL to be stronger than the reference case. In all these instances, polarization has a significant impact on the PL by over $14 \mathrm{~dB}$. This has similarly happened for space number 72 , which is the outdoor case Vista Real. The limited scatterers on the roof in this instance are creating constructive interference and thus reducing the path loss.

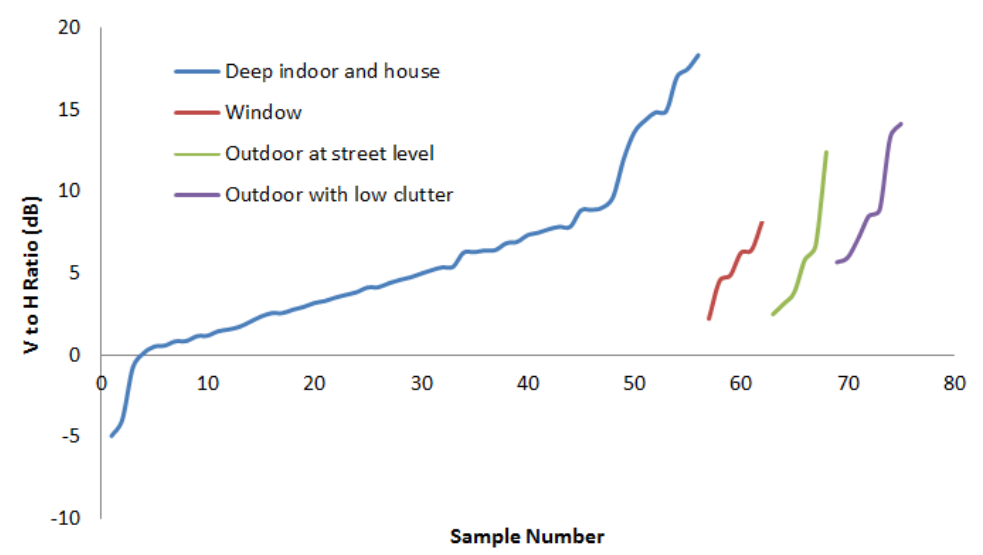

Fig.10. V to $\mathrm{H}$ ratio in ascending order for different samples (spaces). Note the four scenarios are offset on the x-axis for comparison.

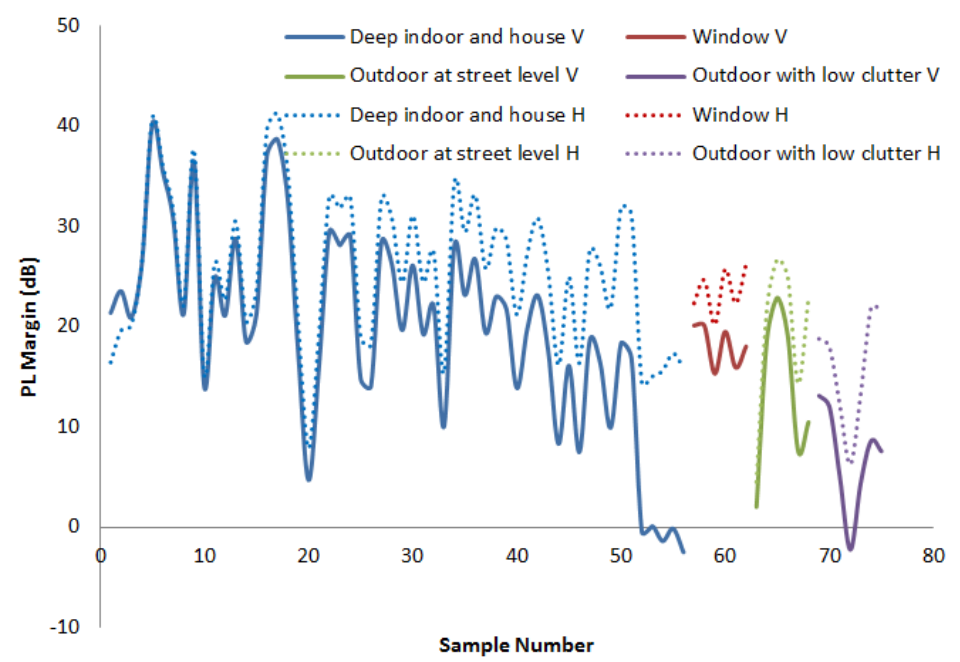

Fig.11. PL margins for designated samples (spaces). Note the four scenarios are offset on the x-axis for comparison.

To assess the effects of floor level compared to the roof level on the PL margin, Figs. 12 and 13 have been included, where data has been grouped according to the level number at which the measurements were taken. 
These levels are also listed in Table A1 (a). Again, the V to $\mathrm{H}$ ratio has been sorted in ascending order for different clusters of levels. For heights above level 1, there is definitely an impact due to polarization, particularly where it is not in a deep indoor case. This is due to the clearer LOS between transmitter and receiver, which preserves the polarization of the incoming wave. Heights at level 1 and below imply more reflections and multipath since the height of surrounding buildings, trees, etc. cause significant depolarization. The instances where the V to $\mathrm{H}$ ratio and PL Margin fall below OdB occur also in Figs. 10 and 11 and are therefore explained where they occurred in the CIMA building.

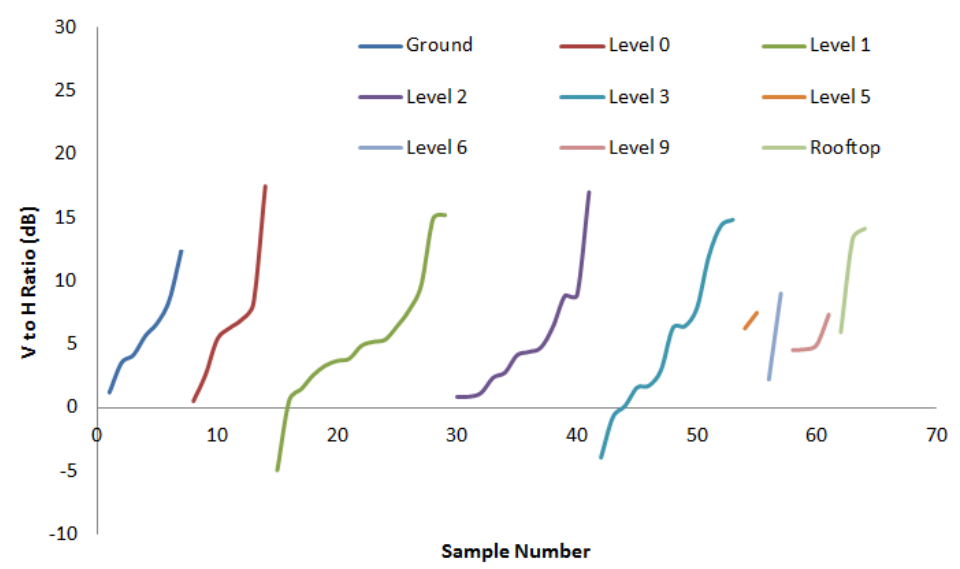

Fig. 12. V to $\mathrm{H}$ ratio floor level effects. Note the nine levels are offset on the $\mathrm{x}$-axis for clarity.

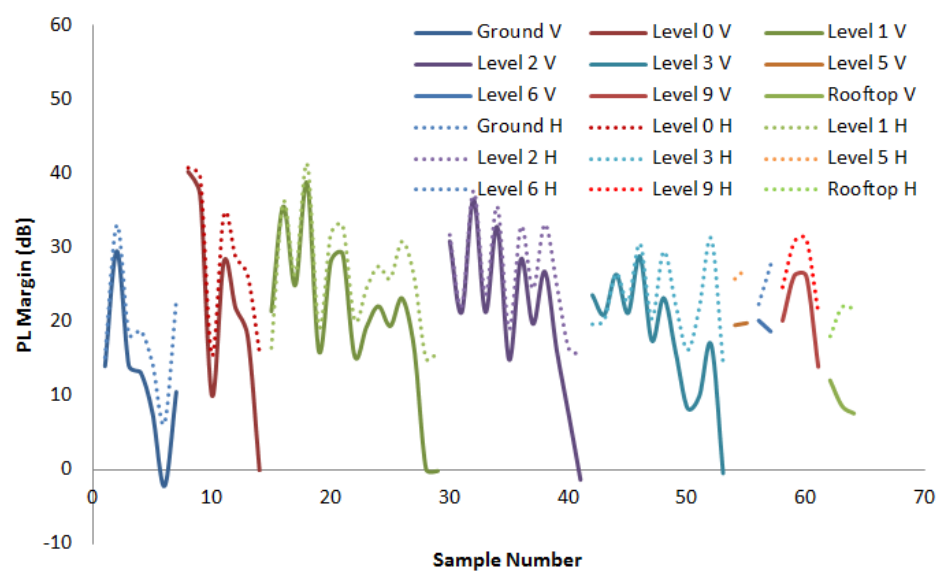

Fig. 13. PL margin floor level effects. Note the nine levels are offset on the $\mathrm{x}$-axis for clarity.

\section{CONCLUSIONS}

A set of dual polarized measurements of transmitted digital broadcasting signals have been measured in both a suburban environment and indoors to gain empirical results of hidden node margin and indicative shadowing margin. Polarization effects are more noticeable in instances where there is less significant clutter around the white space device, such that co-polarization could be used to either decrease the hidden node 
margin for purposes of spectrum sensing or cross-polarization could increase the shadowing margin for purposes of reducing interference to the primary user. Devices near windows and open spaces can benefit from polarization and especially if located at high building levels. On the other hand, de-polarization effects are more evident and pronounced on deep indoor scenarios, reducing the benefit of using a different polarization to protect victim devices, and the margins in either polarization due to clutter there are significantly higher as expected.

Further empirical tests would need to be undertaken to evaluate statistically the expected margin in planning the deployment of white space devices, as well as characterizing more multi-storey buildings to fully assess the effects of building level on polarization and shadowing margins.

\section{APPENDIX}

Table A1 (a) shows the PL margin and V to $\mathrm{H}$ ratios for the different spaces and scenarios for the Queretaro measurement campaign, where the floor level is also indicated. Table A1 (b) shows the corresponding information for the Guildford measurement campaign, where all measurements were conducted at ground level and therefore level is not included.

\begin{tabular}{|c|c|c|c|c|}
\hline Building & Level & Space & $\begin{array}{c}\text { Vertical } \\
\text { PL } \\
\text { Margin } \\
\text { (dB) }\end{array}$ & $\begin{array}{c}\mathrm{V} \text { to } \mathrm{H} \\
\text { Margin } \\
\text { (dB) }\end{array}$ \\
\hline \multirow[t]{5}{*}{ Administrativo } & 0 & Indoor & 28.10 & 6.27 \\
\hline & 1 & Indoor & 40.24 & 0.52 \\
\hline & 2 & Indoor & 36.49 & 1.16 \\
\hline & 3 & Indoor & 21.13 & 1.58 \\
\hline & Roof & Roof & 8.58 & 13.33 \\
\hline \multirow[t]{9}{*}{ Arquitectura } & \multirow[t]{3}{*}{0} & Corridor & -0.16 & 17.49 \\
\hline & & Toilet & 37.18 & 2.57 \\
\hline & & Urban & 10.01 & 5.40 \\
\hline & \multirow[t]{2}{*}{1} & Classroom & 0.20 & 14.93 \\
\hline & & Corridor & -2.42 & 18.34 \\
\hline & \multirow[t]{3}{*}{2} & Classroom & 7.58 & 8.89 \\
\hline & & Corridor & -1.30 & 17.01 \\
\hline & & Toilet & 14.92 & 4.14 \\
\hline & 3 & Corridor & -0.41 & 14.84 \\
\hline \multirow[t]{8}{*}{ Aluas 4} & \multirow[t]{4}{*}{1} & Classroom & 16.40 & 9.65 \\
\hline & & Corridor & 23.11 & 7.71 \\
\hline & & Toilet & 35.52 & 0.59 \\
\hline & & Library & 19.38 & 6.43 \\
\hline & \multirow[t]{2}{*}{2} & Classroom & 26.74 & 6.40 \\
\hline & & Corridor & 19.66 & 4.76 \\
\hline & \multirow[t]{2}{*}{3} & Classroom & 16.86 & 14.35 \\
\hline & & Corridor & 9.91 & 11.97 \\
\hline \multirow[t]{2}{*}{ Biblioteca } & \multirow[t]{2}{*}{1} & Classroom & 24.87 & 1.47 \\
\hline & & Toilet & 38.72 & 2.57 \\
\hline
\end{tabular}




\begin{tabular}{|c|c|c|c|c|}
\hline & & Room & 29.10 & \multirow{2}{*}{$\begin{array}{l}3.86 \\
3.70 \\
\end{array}$} \\
\hline & & Mezzanine & 28.13 & \\
\hline & \multirow[t]{4}{*}{2} & Library & 32.74 & 2.78 \\
\hline & & Offices & 28.46 & 4.40 \\
\hline & & Room & 16.12 & 8.85 \\
\hline & & Room & 30.83 & 0.85 \\
\hline & \multirow[t]{2}{*}{3} & Café & 8.30 & 7.86 \\
\hline & & Terrace & 17.41 & 2.95 \\
\hline \multirow[t]{8}{*}{ CIMA } & \multirow[t]{3}{*}{1} & Lobby & 19.27 & 5.20 \\
\hline & & Toilet & 21.38 & -4.94 \\
\hline & & Workshop & 15.96 & 3.32 \\
\hline & \multirow[t]{2}{*}{2} & Entrance & 21.22 & 0.86 \\
\hline & & Office & 21.27 & 2.36 \\
\hline & \multirow[t]{3}{*}{3} & Classroom & 26.34 & 0.12 \\
\hline & & Corridor & 20.91 & -0.74 \\
\hline & & Toilet & 23.56 & -3.94 \\
\hline $\begin{array}{c}\text { Campestre } \\
\text { Italiana } \\
\end{array}$ & Ground & Wall & 13.11 & 5.68 \\
\hline Marcelina & Ground & Road & 13.95 & 1.19 \\
\hline Tejeda & Ground & Road & 14.06 & 4.16 \\
\hline Vista Real & Ground & Wall & -2.26 & 8.52 \\
\hline \multirow[t]{6}{*}{ Puerta Real } & \multirow[t]{3}{*}{ Ground } & Road & 10.48 & 12.41 \\
\hline & & Road & 7.60 & 6.70 \\
\hline & & Room & 29.50 & 3.53 \\
\hline & \multirow[t]{3}{*}{1} & Room & 23.00 & 6.85 \\
\hline & & Balcony & 17.62 & 7.85 \\
\hline & & Room & 18.36 & 13.62 \\
\hline \multirow{16}{*}{$\begin{array}{c}\text { Technology } \\
\text { Park }\end{array}$} & \multirow[t]{2}{*}{0} & Reception & 21.74 & 6.93 \\
\hline & & Window & 18.03 & 8.20 \\
\hline & \multirow[t]{2}{*}{1} & Corridor & 22.07 & 5.37 \\
\hline & & Window & 15.32 & 4.87 \\
\hline & \multirow[t]{3}{*}{3} & Corridor & 23.16 & 6.30 \\
\hline & & Toilet & 28.79 & 1.74 \\
\hline & & Window & 15.91 & 6.43 \\
\hline & \multirow[t]{2}{*}{5} & Reception & 19.78 & 7.49 \\
\hline & & Window & 19.49 & 6.26 \\
\hline & \multirow[t]{2}{*}{6} & Hall & 18.65 & 9.02 \\
\hline & & Window & 20.12 & 2.23 \\
\hline & \multirow[t]{4}{*}{9} & Corridor & 13.87 & 7.34 \\
\hline & & Room & 26.21 & 4.60 \\
\hline & & Toilet & 26.13 & 4.98 \\
\hline & & Window & 20.10 & 4.55 \\
\hline & Roof & Wall & 12.03 & 5.96 \\
\hline
\end{tabular}

(a) 


\begin{tabular}{|l|c|c|}
\hline Area & $\begin{array}{c}\text { Vertical PL } \\
\text { Margin (dB) }\end{array}$ & $\begin{array}{c}\text { V to H } \\
\text { Margin (dB) }\end{array}$ \\
\hline School (1) & 19.12 & 5.86 \\
\hline Gardner Road (2) & 4.36 & 8.89 \\
\hline Wall (3) & 5.06 & 7.14 \\
\hline St. Margarets (4) & 18.67 & 3.13 \\
\hline Eisenmore (5) & 22.89 & 3.84 \\
\hline Lower Street (6) & 2 & 2.51 \\
\hline Gents Toilets (7) & 18.51 & 2.05 \\
\hline Gents Toilets 2 (8) & 4.68 & 3.19 \\
\hline
\end{tabular}

Table A1. HNM and V to H ratios over the whole broadcast spectrum: a) Queretaro data; b) Guildford data (numbers in brackets are areas as labeled as areas in Fig. 1).

\section{REFERENCES}

[1] D. Gurney, G. Buchwald, L. Ecklund, S.L. Kuffner and J. Grosspietsch, "Geo-location database techniques for incumbent protection in the TV white space,” $3^{\text {rd }}$ IEEE Symp. on New Frontiers in Dynamic Spectrum Access Networks, 2008. DySPAN 2008, pp. 1-9, Chicago, October 2008.

[2] P. Fei, W. Nan, G. Yue, L. Cuthbert and Z. Xing, “Geo-location database based TV white space for interference mitigation in LTE femtocell networks,” 14 1 theE Int. Symp. on World of Wireless, Mobile and Multimedia Networks (WoWMoM), 2013, pp. 1-6, Madrid, June 2013.

[3] M. Denkovska, P. Latkoski and L. Gavrilovska, “Geolocation database approach for secondary spectrum usage of TVWS,” $19^{\text {th }}$ Telecommunications Forum (TELFOR), 2011, pp. 369-372, Belgrade, November 2011.

[4] D. Makris, G. Gardikis and A. Kourtis, “Quantifying TV white space capacity; a geolocation-based approach,” IEEE Comm. Mag., vol.50, issue 9, pp. 145-152, Sept. 2012.

[5] Hou-Shin Chen and Wen Gao, "Spectrum sensing for TV white space in North America,” IEEE J. on Sel. Areas in Comm., vol. 29, issue 2, pp. 316-326, Feb. 2011.

[6] Q. Zhi, Z. Wenyi, S.J. Shellhammer and A.H. Sayed, “Optimal spectral feature detection for spectrum sensing at very low SNR,” IEEE Trans. Comm., vol. 59, issue 1, pp. 201-212, Jan. 2011.

[7] S. Haykin, D.J. Thomson and J.H. Reed, “Spectrum sensing for cognitive radio,” Proc. IEEE, vol. 97, issue 5, pp. 849-877, May 2009.

[8] A. Ghasemi and E.S. Sousa, "Spectrum sensing in cognitive radio networks: requirements, challenges and design trade-offs,” IEEE Comm. Mag., vol. 46, issue 4, pp. 32-39, April 2008.

[9] S.J. Shellhammer, “A comparison of geo-location and spectrum sensing in cognitive radio,” Proc. of $18^{\text {th }}$ Int. Conf. Comp. Comm. and Networks, ICCCN 2009, pp. 1-6, San Francisco, August 2009.

[10] T. W. C. Brown, A. C. H. Tay, "On the Benefits of Polarization for Fixed Area Television White Space Devices", IEEE Transactions on Antennas and Propagation, vol. 62, issue 3, March 2014. 
[11] M. Fadda, V. Popescu, M. Murroni, P. Angueira, J. Morgade, "On the Feasibility of Unlicensed Communications in the TV White Space: Field Measurements in the UHF Band", Interanational Journal of Digital Multimedia Broadcasting, Article ID 319387, 2015. 